\title{
Pbworks e a Construção de Projetos de Aprendizagem
}

\author{
Gláucia Silva da Rosa', Muriel Lago² \\ ${ }^{1}$ Secretaria Municipal de Educação de Canoas - Canoas - RS, Brasil. \\ ${ }^{2}$ Secretaria Municipal de Educação de Farroupilha - Farroupilha - RS, Brasil. \\ glauciabert@hotmail.com, muriellago@yahoo.com.br
}

\begin{abstract}
Resumo $O$ presente artigo analisa o uso do Pbworks como ferramenta pedagógica para a construção de Projetos de Aprendizagens. É uma pesquisa qualitativa na forma de estudo de caso a partir do Curso de Especialização em Psicopedagogia e Tecnologias da Informação e Comunicação na modalidade à distância da Universidade Federal do Rio Grande do Sul. Observou-se que quando os alunos se envolvem num processo colaborativo e cooperativo, eles constroem uma aprendizagem mais significativa entre os agentes do processo de ensino e de aprendizagem.
\end{abstract}

Abstract. This article analyzes the use of PBworks as a pedagogical tool for building Learning Projects. It is a qualitative research in the form of case study from the Specialization in Educational Psychology and Information and Communication Technologies in distance mode of the Federal University of Rio Grande do Sul. It was observed that when students engage in a collaborative process and cooperative, they build a more meaningful learning among agents in the process of teaching and learning.

\section{Apresentação}

Diariamente enviamos emails, mensagens de textos, fazemos pesquisas online, registramos recados no correio de voz, descobrimos telefones e endereços utilizando a internet, postamos fotos em nossos álbuns virtuais, arquivamos documentos em nuvens, entre tantas outras coisas. E isso tudo se torna mais natural a cada dia. Essa naturalidade com que as coisas foram evoluindo e se modificando também se tornou parte do cenário educacional brasileiro.

O ensino que há algum tempo era concebido somente na modalidade presencial passou a ser ministrado também na modalidade a distância, ganhando assim, espaço e tempo nas atividades das pessoas e difundindo-se rapidamente.

Neste contexto, as Tecnologias da Informação e Comunicação (TICs) são ferramentas indispensáveis, confiando credibilidade, seriedade e assegurando meios eficazes no desenvolvimento da aprendizagem, na modalidade de ensino a distância. Ao pensar nas TICs aplicadas à educação, citamos as palavras de Corbellini e Real (2012, p.2) que nos indicam que "os chats, fóruns, lista de discussões, blogs, wikis, e-mails e 
V Congresso Brasileiro de Informática na Educação (CBIE 2016)

Anais dos Workshops do V Congresso Brasileiro de Informática na Educação (CBIE 2016)

outros" são exemplos destas ferramentas, capazes de frutificar a aprendizagem sob outra perspectiva.

É nesse contexto apresentado acima que a proposta de desenvolvimento e pesquisa deste trabalho se insere. Acreditamos, cada vez mais, no potencial de conhecimentos e aprendizagens que podem ser geradas a partir do uso das TICs no ensino a distância, e por isso é que desenvolvemos este estudo de caso a partir da reflexão acerca de uma disciplina do Curso de Especialização em Psicopedagogia e TICs. A metodologia da pesquisa objetivou uma análise qualitativa dos dados de investigação agregando valor às descobertas a partir de revisão bibliográfica. Essa pesquisa teve por objetivo investigar como acontece uma aprendizagem significativa por meio da organização de projetos de aprendizagem com a utilização do Pbworks no ensino a distância.

Este trabalho foi organizado em cinco sessões: a primeira faz uma breve apresentação da temática do trabalho; a segunda apresenta o Pbworks como uma ferramenta pedagógica para o desenvolvimento de atividades na modalidade a distância; a terceira aborda a metodologia de projetos de aprendizagem; a quarta traz o relato de experiência sobre a utilização do Pbworks em uma disciplina para construção de um projeto de aprendizagem e a quinta apresenta algumas considerações finais sobre a investigação.

\section{Pbworks: uma ferramenta pedagógica}

O Pbworks é uma ferramenta eletrônica de trabalho utilizada para a construção de páginas na internet de fácil manuseio, em que são permitidas a edição e alteração de conteúdos, inclusive por meio de arquivos, entre múltiplos usuários. Nesse espaço, as criações ficam por conta dos usuários que podem utilizar links, vídeos, imagens, gifs, textos, enfim, os mais diferentes recursos para comunicar suas intenções, sejam elas educacionais ou profissionais. A criação de uma conta no Pbworks é bem simples e está associada às necessidades dos clientes, que escolhem espaços pagos ou gratuitos de acordo com as condições de armazenamento, workspaces e usuários.

Os workspaces são espaços destinados à construção interativa, e podem ser públicos ou privados, de acordo com os objetivos propostos para a sua utilização. $\mathrm{O}$ responsável pela página pode convidar outros usuários para visitar ou editar seus workspaces. Também há um espaço destinado aos comentários, que pode servir como meio de comunicação entre os usuários da página. A foto do perfil junto ao nome do usuário colabora para a identificação da origem dos comentários deixados.

No caso da página contar com mais de um usuário editor, é possível visualizar o histórico de edição, visualizando os responsáveis pela mesma, recuperando e retornando a versões antigas, caso haja necessidade. Cabe ressaltar que as edições e comentários carregam consigo o registro de data e horário em que foram realizadas, facilitando o controle por parte do administrador da página, tendo em vista os seus objetivos.

Com tantas possibilidades, é visível que o Pbworks oferece benefícios à construção do conhecimento que ocorre de maneira interativa e dinâmica, abrindo caminho à pesquisa, à investigação e à elaboração de relações simples e complexas, no intuito de exigir do aluno uma postura ativa no desenvolvimento de suas aprendizagens. Neste sentido, tutores e alunos reorganizam seus papeis, comprometendo-se cada qual 
V Congresso Brasileiro de Informática na Educação (CBIE 2016)

Anais dos Workshops do V Congresso Brasileiro de Informática na Educação (CBIE 2016)

com suas tarefas: o aluno-pesquisador e o tutor-problematizador. Concordamos com Silveira e Carvalho (in Silva e Ayres, s.d, p.4) quando relatam que "o desafio das propostas pedagógicas em espaços digitais de aprendizagem está na superação das práticas que privilegiem o individualismo, a passividade, o ajustamento e a repetição".

Considerando as ideias apresentadas, a seguir descreveremos a metodologia de trabalho desenvolvido na disciplina de Projetos e Relações de Aprendizagens nos Ambientes Virtuais.

\section{Metodologia de Projetos de Aprendizagem}

Questionar, problematizar e estimular a curiosidade são algumas das tarefas necessárias ao educador, no intuito de provocar a construção do conhecimento nos educandos. Da mesma forma, cabe ao aluno a tarefa de investigar, pesquisar, avaliar hipóteses, testar, verificar e tomar decisões, para reorganizar seus pensamentos e evoluir no seu processo de busca pelo saber.

Nesta perspectiva, entendemos os Projetos de Aprendizagem (PA) como uma metodologia fundamentada numa concepção epistemológica interacionistaconstrutivista-sistêmica. É importante destacar que, segundo Trein e Schlemmer (2009), o projeto não segue uma ordem prévia de suas etapas que são: certezas provisórias; dúvidas temporárias; objetivos; desenvolvimento e sistematização. Sendo assim,

[...] a metodologia pode ser desenvolvida a partir de uma plataforma temática definida ou livre, sendo esta uma decisão coletiva entre estudantes e educadores, que considera desejos, necessidades, atualidade, características da área de conhecimento em questão e propósitos a serem perseguidos. As decisões são heterárquicas e o trabalho se desenvolve num clima de colaboração e respeito mútuo na busca do desenvolvimento da autonomia, da autoria e coautoria, da cooperação e da solidariedade (BACKES e SCHLEMMER, 2013, p.251).

Organizada a partir da plataforma temática de interesses dos alunos, essa metodologia contribui para o desenvolvimento da autonomia e da autoria, tanto individual quanto coletiva, estimulando a colaboração e cooperação entre os sujeitos envolvidos.

A metodologia dos PA vão ao encontro da utilização do Pbworks enquanto ferramenta, pois ambas carregam características similares. A ferramenta Pbworks possibilita a criação, pois nele, não há nada pronto. Cabe ao usuário utilizar sua imaginação e conhecimentos para "fazer nascer" sua página, que pode ser composta pelos mais diferentes recursos, avaliados e escolhidos pelo administrador (aluno), no intuito de tornar-se atraente e confiável, de acordo com os objetivos a que se propõe. De modo similar, a metodologia dos PA confere ao aluno uma postura de busca autônoma, que exige investigação, reflexão e tomada de decisões. Sendo assim, ambos se tornam mecanismos de construção coletiva.

\section{Relato de experiência: a construção de um PAno Pbworks}

O presente relato apresenta um trabalho desenvolvido durante a disciplina de Projetos $e$ Relações de Aprendizagem nos Ambientes Virtuais do Curso de Especialização em 
V Congresso Brasileiro de Informática na Educação (CBIE 2016)

Anais dos Workshops do V Congresso Brasileiro de Informática na Educação (CBIE 2016)

Psicopedagogia e TICs da UFRGS, no Polo de São Francisco de Paula. O objetivo da disciplina era promover o contato das alunas com a metodologia de ensino dos PA a partir do uso das TICs, no intuito de refletir acerca da sua viabilidade e dos benefícios de sua aplicação no âmbito educacional.

De acordo com as professoras responsáveis pela disciplina em questão,

\begin{abstract}
Os projetos de aprendizagem são apresentados como fontes de inspiração para a construção e planejamento de práticas pedagógicas em sala de aula, nas quais a interação, interdisciplinaridade, autonomia e autoria são elementos fundamentais em um processo de produção de conhecimento acerca do que os alunos verdadeiramente querem aprender. As propostas para o desenvolvimento desses projetos devem ser construídos em torno do levantamento e exploração de perguntas feitas pelos alunos, oriundas dos seus interesses de aprendizagem (REAL e HERNANDEZ, 2015).
\end{abstract}

Sendo assim, o desenvolvimento da proposta ocorreu em etapas complementares que fomentaram o estudo, a reflexão e posteriormente a aplicação das aprendizagens. Após realizarem leituras referentes à importância de desenvolver nos alunos o espírito investigativo e curioso, as alunas do curso foram solicitadas a lançar, em um fórum, perguntas para as quais ainda não tinham resposta, que partissem de suas curiosidades e de seus interesses.

Segundo Piaget (1976), em sua teoria sobre o processo de aprendizagem, a construção do conhecimento não pode ser compreendida apenas pela estrutura interna do sujeito. $\mathrm{O}$ autor apresenta o processo como resultado da interação do sujeito com o objeto, não existindo conhecimento resultante de um simples ato de observação. Sendo assim, se faz necessário perceber a importância da reflexão, da perturbação e do questionamento.

No contexto deste relato, a primeira pergunta e dificuldade que o grupo trouxe foi: “O que perguntar?". Percebemos que a dificuldade em questionar não é uma afirmação de que conhecemos ou sabemos tudo, e sim um reflexo da educação a que fomos submetidos, na sociedade, na família, e na escola. Nascemos curiosos, sedentos pelo saber, porém pouco a pouco, pelas influências do meio social e educacional, essas curiosidades são banidas, julgadas, até tornarem-se adormecidas.

Em contrapartida, temos ciência de que são as perguntas que nos movem, que nos incentivam e nos motivam na busca pelo saber. Deste modo, para formar alunos pesquisadores, precisamos, antes de mais nada, assumir uma postura de professor investigador e pesquisador adotando atitudes de curiosidade, observação e temporárias, questionamentos, afim de tomar as certezas como provisórias e as dúvidas como concebendo a flexibilidade da informação a partir de nossa capacidade de reflexão acerca dela.

Transgredido o período de divulgação das curiosidades em forma de pergunta, foram organizados no Pbworks os grupos de trabalho. Constituíram-se seis grupos de acordo com a afinidade das curiosidades que foram apresentadas no fórum inicial.

Deste momento em adiante, passaríamos por uma mudança de postura na construção do conhecimento, que alterava seu modo individual para coletivo. A partir da pergunta inicial registrada no fórum, organizou-se uma tabela que contava com duas colunas: certezas provisórias e dúvidas temporárias. Nesse espaço, cada componente do 
V Congresso Brasileiro de Informática na Educação (CBIE 2016)

Anais dos Workshops do V Congresso Brasileiro de Informática na Educação (CBIE 2016)

grupo registrou o que julgava ter certeza sobre o tema em discussão, lançando também as suas dúvidas. Destacam-se os termos, "provisórias" e "temporárias", tendo-se em vista a transitoriedade dos conhecimentos que adquirimos. Nada é estável, pelo contrário, na busca pelas informações, as ideias se recompõem à luz de nossas pesquisas, ganhando outros enfoques e direcionalidades.

Ao final desta etapa foram registradas 149 "dúvidas temporárias" que emergiram de 80 "certezas provisórias". Relacionando esta etapa com a etapa inicial de lançamento de perguntas no fórum, pudemos perceber o avanço dos grupos, que se permitiram questionar, que refletiram e, a partir de suas reflexões, identificaram elementos e ideias que não conheciam por completo, e, portanto, mereciam a pesquisa e a investigação.

Após a etapa inicial do trabalho e também de familiarização com o PBworks, iniciou-se o desenvolvimento da pesquisa e investigação, que tinha por objetivo testar as hipóteses descritas, analisando-as e reorganizando-as de acordo com as descobertas que vinham sendo realizadas. Buscando a ampliação de seus conhecimentos sobre o assunto, os alunos utilizaram recursos da internet, buscando vídeos, imagens e leituras que contribuíssem com a investigação. Ao pesquisar suas dúvidas, as alunas também estavam questionando ou reafirmando suas certezas temporárias, pois uma leitura, um vídeo, ou outro material, poderia, ao mesmo tempo em que sanava a dúvida, desmitificar uma certeza.

Pouco a pouco, o workspace do Pbworks foi preenchido de informações complementares com um tema em comum, que precisavam ser organizadas de modo a compor uma escrita colaborativa e uniforme, que traduzisse as descobertas e conclusões do grupo sobre o assunto.

O trabalho de escrita colaborativa no Pbworks requereu mais atenção dos alunos e dos tutores, ambos participantes do processo. Era necessário que se fizesse uma leitura minuciosa, selecionando aquilo que seria reorganizado, e, talvez, retirado do workspace, analisando informações que se repetiam e outras que se complementavam, enfim, amarrando as ideias na construção de uma escrita coerente e coesa, que traduzisse os objetivos que o grupo havia se proposto a atingir.

Cabe destacar que, durante a organização de todo trabalho, enquanto o Pbworks se tornava ferramenta de criação, registro e interatividade, tutoras e estudantes buscaram o estabelecimento de uma comunicação clara, que fosse eficaz ao bom andamento das atividades. Neste caso, além da utilização da troca de mensagens por correio eletrônico, foram utilizados os contatos via telefone, a fim de que os estudantes criassem uma relação mais ágil e pontual com as tutoras, resolvendo possíveis dúvidas apresentadas inicialmente.

Além das ferramentas acima citadas, as mensagens enviadas via Moodle também foram de grande valia no processo. Nas mensagens, foram utilizadas chamadas para trazer os alunos ao compromisso de participar do processo de construção do PA. Como chamada para esta tarefa em equipe foram utilizadas mensagens semelhantes a esta que segue: 
V Congresso Brasileiro de Informática na Educação (CBIE 2016)

Anais dos Workshops do V Congresso Brasileiro de Informática na Educação (CBIE 2016)

Olá cursistas!

Na página do grupo no Pbworks, a colega E. já iniciou a escrita de um texto colaborativo de introdução. Vamos lá! Passem por lá, editem a página e vão adicionando suas ideias para contribuir com a introdução do trabalho (lembrem de assinalar seus nomes no final da escrita, para marcar a autoria). Após, iniciem, ao final das postagens do grupo, uma breve escrita colaborativa para compor uma conclusão do mesmo.

O trabalho de vocês já conta com várias fontes e materiais interessantes. Vamos alinhar essa parte (introdução e conclusão) para aproximar as informações contidas nele.

Aguardo vocês por lá!

Aos poucos, pudemos acompanhar os grupos na organização das escritas colaborativas da introdução e da conclusão, bem como na organização do conteúdo de desenvolvimento das pesquisas realizadas. À medida que foram estimulados e instigados a participar, os alunos lançaram-se novamente na caminhada de busca pelo saber, estabelecendo relações e construindo saberes nas trocas vivenciadas. Também, pouco a pouco, aventuraram-se no sentido de ganhar autonomia, buscando por si só meios de contato com os colegas, incitando a participação de todos na elaboração do trabalho.

Como resultado, tivemos Projetos de Aprendizagens bem elaborados, constituídos como uma trama das "certezas provisórias" e das "dúvidas temporárias" de cada grupo, carregados de criticidade, empatia, respeito e, acima de tudo, colaboração.

\section{Considerações finais}

Acompanhando esta proposta de construção de Projetos de Aprendizagem no Pbworks foi possível evidenciar a importância do olhar atento para o processo de aprendizagem de cada aluno, visto que, cada qual traz consigo suas particularidades, habilidades e impedimentos. Superadas as dificuldades e construídas as aprendizagens, os alunos refletiram acerca da proposta e interagiram com outros grupos, lendo e contribuindo com seus trabalhos.

Com isso, destacaram-se em seus relatos a importância da interação e das trocas de experiências contidas nessa 'nova forma de aprender'. Um aprender que se alicerça nos interesses dos alunos e em suas descobertas. Um aprender flexível no tempo e espaço, que é organizado, retomado e planejamento tantas vezes for necessário, no intuito de gerar uma aprendizagem significativa. Um aprender que é solidário e, portanto, ampara. Um aprender que permanece, na medida em que o aluno se torna cientista e autor, a medida em que ele pesquisa, analisa, interpreta e reformula seus conhecimentos.

Acompanhando o desenvolvimento de todo o trabalho, pudemos observar que os PAs encantaram seus participantes/alunos, mostrando-se uma proposta inovadora aliada às TICs e, portanto, adequada ao cenário educacional contemporâneo. 


\section{Referências}

BACKES, Luciana. SCHLEMMER, Eliane. Práticas pedagógicas na perspectiva do hibridismo tecnológico digital. Revista Diálogo Educacional (PUCPR). v. 13, n. 38, p.243-266. 2013.

CORBELLINI, Silvana; CORTE REAL, Luciane Magalhães. Caleidoscópio: as multivisões facetadas da pesquisa cooperativa na educação à distância. In: Simpósio Internacional de Educação a Distância SIED 2012 e Encontro de Pesquisadores em Educação a Distância EnPED 2012, São Paulo, Anais do SIED, 2012.

PIAGET, J. A equilibração das estruturas cognitivas. Rio de Janeiro: Zahar, 1976.

REAL, Luciane Magalhães Corte; HERNANDEZ, Evelyse Ramos Itaqui. Disponível em: https://moodle.ufrgs.br/course/view.php?id=29575. Acesso em: 09/12/2015.

SILVA, Albina Pereira de Pinho; AYRES, Sandra Regina Braz. O uso do Pbworks como espaço digital de aprendizagem - minicurso.S.d. Disponível em http://sinop.unemat.br/v-semi-info-edu/wpcontent/uploads/2013/07/uso_do_pbworks_como_como_espaco_digital_de_aprendizag em.pdf. Acesso em: 08/12/2015.

TREIN, D.; SCHLEMMER, E. Projetos de Aprendizagem baseados em Problema no Contexto da web 2.0: possibilidades para a prática pedagógica. Revista e-Curriculum, v. 4, p. 1-20, 2009. 